\title{
Greenhouse Protection Against Frost Conditions in Smart Farming using IoT Enabled Artificial Neural Networks
}

\author{
Dr. Joy Iong-Zong Chen, \\ Department of Electrical Engineering, \\ Da-Yeh University, \\ Dacun, Changhua, \\ Taiwan.
}

\author{
Lu-Tsou Yeh, \\ Department of Electrical Engineering, \\ Da-Yeh University, \\ Dacun, Changhua, \\ Taiwan.
}

\begin{abstract}
An Artificial Intelligence and IoT incorporated frost forecasting is proposed in this novel work. The objects present inside a greenhouse are connected to each other through Internet of Things (IoT), using devices such as actuators, sensors and assisting aids. A smart system incorporating IoT is designed, developed and implemented using Fuzzy associative memory and Artificial Neural Networks (ANN) in order to manage any ill effects in irrigation caused due to frost conditions. The temperature inside the green house is monitored continuously on comparison with the outside temperature, thereby steps are taken to stabilize the temperature to make it suitable for plant growth. The temperature inside the greenhouses are forecasted by means of ANN and using fuzzy control, temperature of the crops are predicted and watered as per the required using 5 levels of water pump output. The output obtained is analyzed and compared with similar Fourierstatistical method and it is found that the proposed methodology provides a more effective prediction of temperature.
\end{abstract}

Keywords: Greenhouse, artificial neural network, fuzzy control, temperature monitoring, internet of things, agriculture

\section{Introduction}

The crops and plants growing in areas of very low temperature are exposed to frost which leads to severe effects on plant development. In fact, it has been identified that frost damage is one of the most dangerous agent capable of damaging a plant tissue's cell [1]. This formation of frost due to geomorphic change is due to cooling depth in farmland, relative humidity and air temperature. Meanwhile, it is possible to control these changing geomorphic conditions to control the temperature inside the greenhouse thereby protecting the crop against climatic adversity. In recent years, Artificial intelligence has been used to a large extent to improve and increase production rate by means of self-optimized and smart industrial facilities and equipments that are built to meet the growing demand of food, worldwide [2-3]. The proposed work will involve the employment of smart farming solutions, application and technologies for the betterment and improvement of food production [4].

The ultimate challenge of the agroindustry is using minimal carbon footprint to reduce the carbon content in the air [5]. If the microclimate of the green houses are properly maintained and monitored such that there is no harmful impact of frost and a proper mechanism is built to stop frost formation within the greenhouse, the impact to the growth of crops will be high. In such conditions, it is also possible to determine the usage of water dispersion system that is used to prevent plasticized surface form freezing [6]. The working idea behind this concept is that the internal heat emancipated doesn't move out by thermal capacitance and thermal insulation due to low temperatures and low plastic porosity. A proper water sprinkler system is used along with this greenhouse, resulting in the formation of a layer of ice [7]. Using this novel invention, it is possible to eliminate impact of temperature changes that impact the growth of crops inside the greenhouse, making it into an igloo [8]. Fourier-statistical analysis of a similar system that uses prediction of temperature and humidity on an hourly basis with the help of an intelligent weather station operating on the basis of neural networks through smart frost control management [9]. In addition, the use of IoT cellular communication network will provide an enhanced means to keep tract of and remote access to the information that is saved on the web server. 
Journal of Electronics and Informatics (2020)

Vol.02/ No.04

Pages: 228-232

https://www.irojournals.com/iroei/

DOI: https://doi.org/10.36548/jei.2020.4.005

When the air temperature drops below 0 degree calcium, liquids tend to initiate the freezing process. Hence, when frost occurs, it will also begin to freeze when the temperature moves towards null. In order to identify the extent of damage dues to frost and drop in temperature, samples of crops at similar temperatures are measured. Based on the observation, the damage impact of these crops is identified [10]. Dry cold and humidity have a direct impact on the tissues in the plant, resulting in complete destruction of these internal cells based on the different crops that are exposed. Some crops such as maguey, bean and corn show damage in the cell tissues leading to a heavy loss in financial means [11-12]. The black frosts in central Mexico are typical examples of disastrous weather leading to destruction of agricultural crops. Recent studies include the development of a solar greenhouse based on thermal storage that is used to increase the temperature inside the greenhouse by raising the air temperature by means of water solar heating. But, the major disadvantage of using solar energy to provide thermal atmosphere is not possible in areas where frost occurs on a regular basis [13].

\section{Methods and Materials}

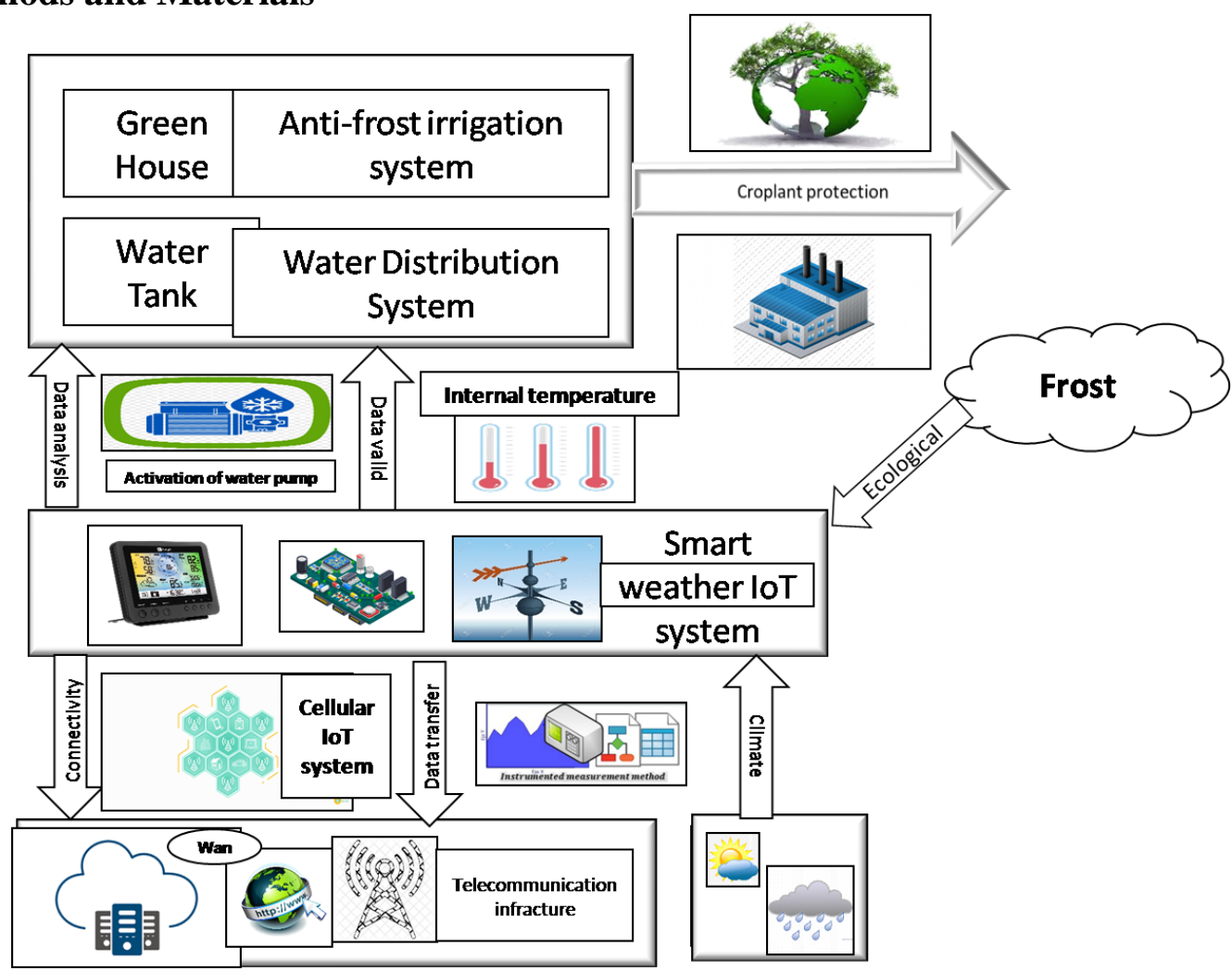

Fig.1. Smart Farming Methodology

The proposed work is implemented in the state of Mexico, using an intelligent system prototype. A greenhouse that grows tomato species is built such that the species is exposed to various earthly climate representing recurrent block frost to determine the impact and effect on final species yield. Fig.1 show the step-by-step methodology used to design and develop the smart farming methodology.

\subsection{Wireless Network Connections}

The first step involves gathering of data from the meteorological station using a wireless protocol (such as Xbee-Wi-fi). The obtained information is further modified with the help of a protocol exchanger device in order to ensure safe and secure transmission of data. A GPRS/GSM cellular network device and micro SD card is also used along with the driver. This station is built with self-sustainable power back up generated by means of solar cells with the help of a DC/DC converter, a $12 \mathrm{~V}$ battery and a charge controller. Using wireless technology information, the external remote weather station is built and is used to gather information on parameters such as temperature, solar radiation, relative humidity, barometric pressure. They are further connected to sensors that determine GPS, rain gauge, relative humidity, wind direction and wind speed. In general a weather shield should hold signal translators and voltage regulators which are further integrated with the different parameters recorded by the weather station that comprises of information that can accessed by means of serial port communication. 
Journal of Electronics and Informatics (2020)

Vol.02/ No.04

Pages: 228-232

https://www.irojournals.com/iroei/

DOI: https://doi.org/10.36548/jei.2020.4.005

\subsection{Internet of Things with Embedded System}

To communicate with greenhouses that are situated in rural as well as remote areas which are not easily accessible, IoT systems are the best options. In this proposed work an M2M smart cellular system is used which is more secure in terms of vulnerability to attacks as well as privacy. Using IoT the following steps are incorporated:

1. Information on weather obtained from the weather station is concatenated and transmitted by means of a wireless device.

2. Protection of the crops in the green house using intelligent forecasting is implemented. Here, the frost temperature is predicted and accordingly an intelligent frost irrigation methodology is proposed using mathematical models.

\section{Proposed Work}

Based on user availability, it is possible to control and monitor information either manually or automatically.

\subsection{Methodology}

There are three major methodologies involved in the proposed work:

- Data Analysis: The data used is analysed with the help of embedded software. A simple excel belonging to Microsoft family is used to save the database and collection of data is obtained by using a Linux platform to run $\mathrm{C}++$ along with a neuroprocessor. Hence the proposed work uses Neural Networks and Fuzzy systems in combination with artificial intelligence via a web page. Relative humidity in inner air, solar radiation, wind speed, relative humidity of outdoor air and temperature of outdoor air are some of the factors which influence frost behaviour. Along with these factors, culture temperature is also taken into account to develop the fuzzy system.

- Data Collection: Using protocol exchanger, data which is gathered is manipulated and saved. A syntactic lexicon analyzer is used to defragment the data and the data that is gathered in this manner is saved onto an SD card. This saved data can be called later on by a GPRS/GSM through a Wireless Application Protocol (WAP). To see the data reflected on the website, a typical TCP/IP control is generated.

- Data Validation: Apart from the use of quantitative measures used to determine the model's performance like standard deviation, mode and mean, specific statistical indices are used to choose the apt ANN architecture. This is chosen depending on analysis of estimated and real values obtained from the ANN. As per the standard error prediction, we can determine the coefficient of $C^{2}$ using the following equation, keeping in mind that the value should be bear 1 for a perfect match.

$$
C^{2}=1-\sum_{i=1}^{N}\left(z_{i}-\widehat{z}_{l}\right)^{2} / \sum_{i=1}^{N}\left(y_{i}-\widehat{y}_{l}\right)^{2}
$$

Where $y_{i}$ and $z_{i}$ represents the actual values calculated while $\widehat{y}_{l}$ and $\widehat{z_{l}}$ indicates the estimated value.

\subsection{Analysis of the Proposed Work}

An efficient form of algorithm that is capable of learning from experience is the Artificial Neural Network (ANN). Their capability is based on their ability to use data and signal to learn and adapt using adaptive, distributed and parallel computing framework. ANN makes it possible to study a set of data and predict the output of the same, provided the system comprises of a combination of synaptic weights and inputs. This can be mathematically represented as:

$$
y=F\left(\sum_{a=1}^{A} \sum_{b=1}^{B} w_{|b x a|} x_{|a x 1|}-b_{|b x 1|}\right.
$$

In this model of matrix, $|b x a|$ of a inputs and $\mathrm{b}$ neurons are defined. Accordingly, every neuron holds a threshold range such that for $w_{|b x a|}$ the value of a is $1,2 \ldots . \mathrm{A}$ and $\mathrm{b}$ is $1,2, \ldots \mathrm{B}$ neurons.

If the input vector is a, $w_{|b x a|}$ is the synaptic weight and $b_{|b x 1|}$ is a constant, then the sigmoid function $\mathrm{F}$ can be defined as the following expression:

$$
F=\frac{1}{1+e^{x}}
$$


Journal of Electronics and Informatics (2020)

Vol.02/ No.04

Pages: 228-232

https://www.irojournals.com/iroei/

DOI: https://doi.org/10.36548/jei.2020.4.005

The learning environment of the neural network, indicates a corresponding change in synaptic weight which can be represented as

$$
\Delta F_{R}=\Delta F(\varphi+\Delta \varphi)-F(\varphi)
$$

When the value of $\Delta F_{R}>0$, the performance of the system will tend to increase. Based on the rules imposed, the correction of the weights are also done.

\section{Results and Discussion}

A thin layer of about $1 \mathrm{~cm}$ on top of the greenhouse is made of plastic. Global solar radiation flux, air relative humidity, outside air temperature and wind speed are the factors taken into consideration. Accordingly, a specific day and time is set to examine the sampling information within periodically, every 15 minutes. Fig.1. represents the summer season exhibition of the greenhouse using ANN.

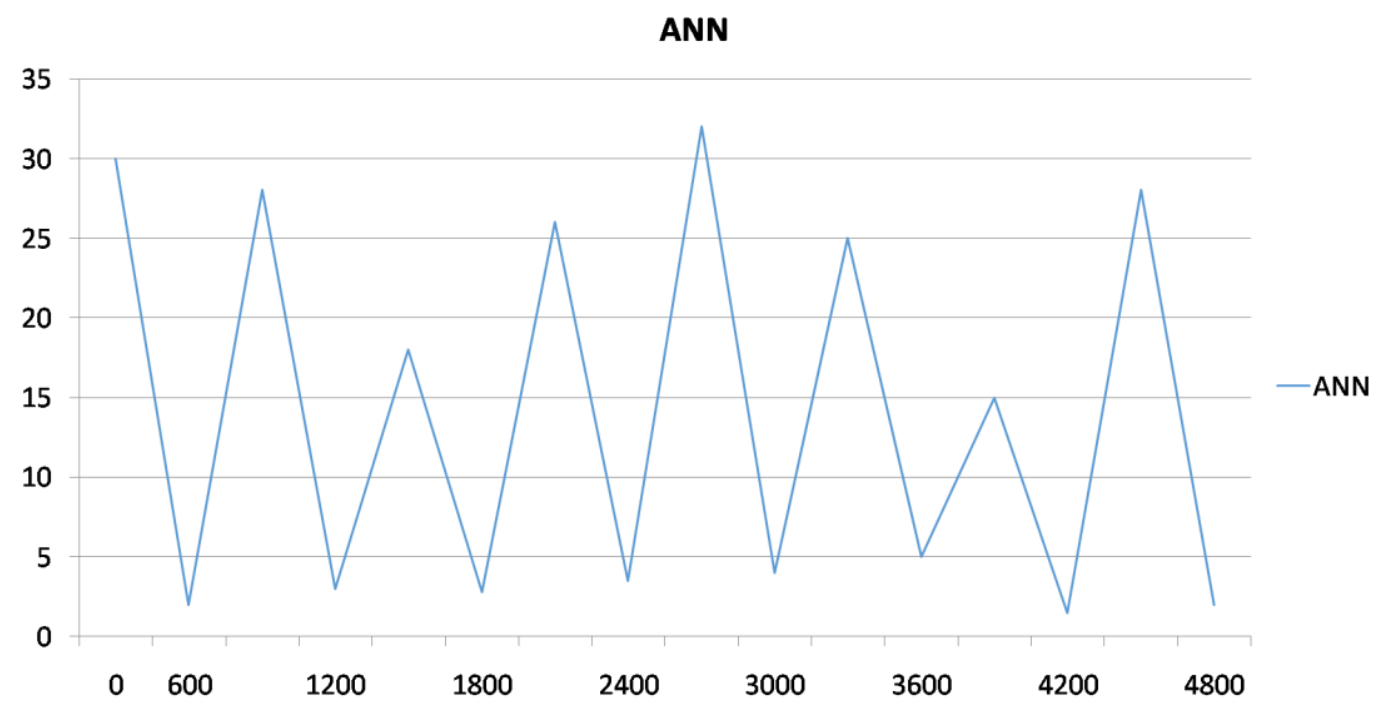

Fig.2. Sampling in Summer Season

In Fig.3, the condensation of water is defined to be the difference in warm water and cold water density. This indicates that when frost is present, it will result in the formation of a thin layer of plastic on the greenhouse.

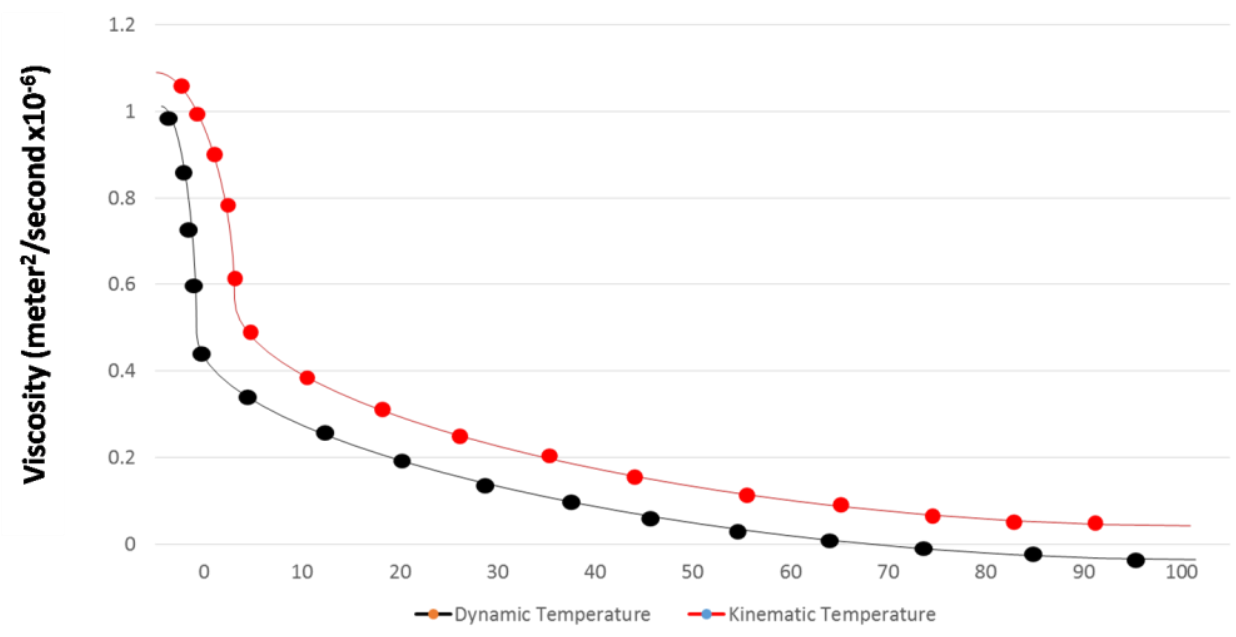

Temperature $\mathrm{T}$ (degree Celsius ${ }^{\circ} \mathrm{C}$ )

Fig.3. Cold and hot water density with respect to temperature 
Journal of Electronics and Informatics (2020)

Vol.02/ No.04

Pages: 228-232

https://www.irojournals.com/iroei/

DOI: https://doi.org/10.36548/jei.2020.4.005

\section{Conclusion}

In this paper a smart farming methodology is introduced by means of fuzzy watering system to preserve the heat content inside the greenhouse. A prediction unit to predict the weather is introduced along with a temperature detector inside the greenhouse, to monitor the weather continuously. An artificial neural network is used in the prediction unit and using backward propagation, analysis is conducted. When the temperature goes beyond the pre-defined level, a thin layer of frost is said to form and this layer can be used to preserve the heat inside, forming an enclave of igloo. This implementation can also incorporate communication of data and alertness to the farmers to monitor the temperature in the atmosphere to protect their crop.

\section{References}

[1] He, F., \& Ma, C. (2010). Modeling greenhouse air humidity by means of artificial neural network and principal component analysis. Computers and Electronics in Agriculture, 71, S19-S23.

[2] Mudd, G. M., Weng, Z., Memary, R., Northey, S., Giurco, D., Mohr, S. H., \& Mason, L. M. (2013). Future greenhouse gas emissions from copper mining: assessing clean energy scenarios.

[3] Shirley, D. R. A., Ranjani, K., Arunachalam, G., \& Janeera, D. A. (2020). Automatic Distributed Gardening System Using Object Recognition and Visual Servoing. In Inventive Communication and Computational Technologies (pp. 359-369). Springer, Singapore.

[4] Taghavifar, H., \& Mardani, A. (2015). Prognostication of energy consumption and greenhouse gas (GHG) emissions analysis of apple production in West Azarbayjan of Iran using Artificial Neural Network. Journal of Cleaner Production, 87, 159-167.

[5] Singh, V. K., \& Tiwari, K. N. (2017). Prediction of greenhouse micro-climate using artificial neural network. Appl. Ecol. Environ. Res, 15(1), 767-778.

[6] Raj, J. S. (2019). A comprehensive survey on the computational intelligence techniques and its applications. Journal of ISMAC, 1(03), 147-159.

[7] Trejo-Perea, M., Herrera-Ruiz, G., Rios-Moreno, J., Miranda, R. C., \& Rivasaraiza, E. (2009). Greenhouse energy consumption prediction using neural networks models. training, l(1), 2.

[8] Khoshnevisan, B., Rafiee, S., Omid, M., Yousefi, M., \& Movahedi, M. (2013). Modeling of energy consumption and GHG (greenhouse gas) emissions in wheat production in Esfahan province of Iran using artificial neural networks. Energy, 52, 333-338.

[9] Zakaluk, R., \& Ranjan, R. S. (2006). Artificial neural network modelling of leaf water potential for potatoes using RGB digital images: a greenhouse study. Potato Research, 49(4), 255-272.

[10] Salazar, R., López, I., \& Rojano, A. (2007, November). A neural network model to control greenhouse environment. In 2007 Sixth Mexican International Conference on Artificial Intelligence, Special Session (MICAI) (pp. 311-318). IEEE.

[11] Taki, M., Ajabshirchi, Y., Ranjbar, S. F., Rohani, A., \& Matloobi, M. (2016). Heat transfer and MLP neural network models to predict inside environment variables and energy lost in a semi-solar greenhouse. Energy and Buildings, 110, 314-329.

[12] Escamilla-Garcia, A., Soto-Zarazúa, G. M., Toledano-Ayala, M., Rivas-Araiza, E., \& Gastélum-Barrios, A. (2020). Applications of Artificial Neural Networks in Greenhouse Technology and Overview for Smart Agriculture Development. Applied Sciences, 10(11), 3835.

[13] Vijayakumar, T. (2019). Neural network analysis for tumor investigation and cancer prediction. Journal of Electronics, 1(02), 89-98. 